\title{
Research of Wellness Tourism in Suburban Area of Changchun City
}

\author{
Yuting Zhang, Lei Li \\ Changchun Science and Technology College, Research Center of Jilin Characteristic Tour Culture \\ Industry Jilin 130600, China
}

Keywords: Wellness Tourism; Suburban; Changchun.

\begin{abstract}
In the wake of analyzing the background of the newly developing wellness tourism in suburban area of Changchun city, this paper advances the progress in researching the formation and rising of suburban tourism and wellness tourism, and the in-depth significance and the main types of wellness tourism in suburban area are clarified by this paper hereof. The resource of wellness tourism in suburban area of Changchun city is introduced, and the current situation and adequacy of the tourism resource, supporting facilities and market of tourism are further analyzed and evaluated. Through the overall planning and guidance conducted by government, the accurate market orientation and the capturing correct development type of wellness tourism resource, the strategy of marketing wellness tourism are further explored in various suburban areas being different and unique respectively.
\end{abstract}

\section{Research Background}

As the economic development in the Northeast part and the rest parts of China is constrained by the downturn, the tourism in Jilin province still maintained the favorable momentum in fast and steady development. With reference of the statistics reported by the Tourism Administration of Jilin province, in the first half of 2015, this province possesses about 68.862 million tourist arrivals, with the year-on-year growth of $16.16 \%$, which stands above the increasing rate estimated by state for about 7 percentages. As the urbanization advances in cities of China, the General Office of the State Council has implemented the National Outline for Mass Tourism and Leisure (effective from 2013 to 2020) since 2013, as to reinforce the infrastructure construction for mass tourism and leisure, to advance the construction deeply in recreational and leisure parks in cities, recreational belts around the cities in cities and the special tourism resorts, and to build the leisure space for mass people.

In 2013, the rate of urbanization of Jilin province has reached $54.2 \%$, which is above the national average. The demand is increasing for wellness tourism in suburban areas of residents mainly from major cities of Jilin province like Changchun, Jilin and Siping, which can demonstrate the improving of living standards of Jilin residents. China has always attached great importance to the well-being and health of residents. At the end of 2014, the aging population in Jilin province was 4.69 million, increasing 1.07 million people compared with the aging population of 3.62 million in accordance with the Sixth Population Census, occupying $17 \%$ of the overall population compared with the previous $13.2 \%$, presenting the growth rate more than $6 \%$. All these data illustrate that the aging of population is booming rapidly. Accordingly, the wellness tourism in suburban areas of Changchun city is able to develop as the Jilin province has favorable developing prospects, the urbanization of Jilin is progressively advanced and the aging phenomenon is deepened.

\section{Definition and Main Types of Wellness Tourism in Suburban Areas}

The wellness tourism in suburban areas means to provide tourists with the touring experience promoting their physical and psychological health in the transitional zone between urban areas and rural areas. The wellness tourism in suburban areas (belt) consists of agricultural wellness tourism, ecological wellness tourism, wellness tourism in forest, hot spring wellness tourism, traditional Chinese medicine wellness tourism and ice and snow wellness tourism. 


\section{Brief Introduction of Resource of Wellness Tourism in Suburban Areas of Changchun City}

The wellness tourism resource in suburban areas of Changchun city is mainly scattered in four areas. From southeast direction, there are Dahei Mountain tourism resources concentrative region and Jingyuetan tourism resources concentrative region, and the major tourist attractions are Jingyuetan National Forest Park, Changchun Movie Wonderland, Xinlicheng Reservoir and Tianyi Hot Spring Resort; From the southwest direction, there is Shuangyang tourism resources concentrative region, and the major tourism attractions are Diaoshuihu National Forest Park, Sika Deer Base for Cultivation and Trade, Yulong Hot Spring Resort, Guoxin South Mointain Hot Spring Hotel, Yuanshan Lake Agriculture Garden, Heiyushu Grape Picking Garden; There is Lianhuashan ecological tourism Resort tourism resources concentrative region, and the major tourism attractions, are Lianhuashan Ski Field, Lianhuashan Resort and Lianhuashan International Central Leisure area. This area attaches great importance to the forest wellness tourism, ecological wellness tourism, agricultural wellness tourism and hot spring wellness tourism. From the northeast direction, there are Songhua River region and Zhangka Manchu village along the side of Songhua River, and this place attaches great importance to the folk culture wellness and rural tourism and Binjiang leisure wellness tourism; From the northwest direction, there are Liao and Jin culture and wet land tourism resource concentrative region, and the major tourism attractions are Boluo River, large-scale wet land in Taiping pool. This place is featured with Liao and Jin culture and wet land wellness tourism.

\section{Analysis and Evaluation towards Tourism Resource, Supporting Facilities and Consumer Market of Wellness Tourism in Suburban Areas of Changchun City}

(1) The tourism resources of wellness tourism in Changchun city are abounded in categories but lack of scarcity. Except the Jingyuetan National Scenic Area, the other tourism attractions are being relatively unknown. Also, the development of tourism is not perfectly geared into the planning of tourism as tourism development will be frequently shifted into the real estate development without exploring the favorable or adequate position in tourism market. Some attractions in Changchun are now developing independently, lacking of exploring the historical culture in the regions. Additionally, the repeated construction of attractions has failed to highlight the characteristics of each attraction and greatly wasted the tourism resources.

(2) Supporting Facilities of Tourism. As the wellness tourism in suburban areas of Changchun city started relatively late, its corresponding supporting facilities continue to be perfected. Here are the following examples. In transportation, the attractions have no bus route or are not equipped with tourism special line for passenger transport. The tourist spots being exurban are not nearly surrounded by tourist hotels. Attractions have deficiency in public washrooms and are substandard in sanitary condition. The places for tourist recreation and shopping are deficient in attractions, which is a relatively serious problem.

(3) Tourist Market for Wellness Tourism in Suburban Areas of Changchun City. The research and analysis have shown that tourist is motivated to participate into the wellness tourism as he look forward to releasing pressure, working out, cultivating moral characters and turning back to nature. The essence of developing wellness tourism is shown as in Figure 1. As shown in Figure 2, the time of people choosing to participate into the wellness tourism is not concentrated. Accordingly, developing the wellness tourism is able to alleviate and revive the downturn of tourist off-season. The tourism resources are no longer being idle but being efficiently and adequately used. 


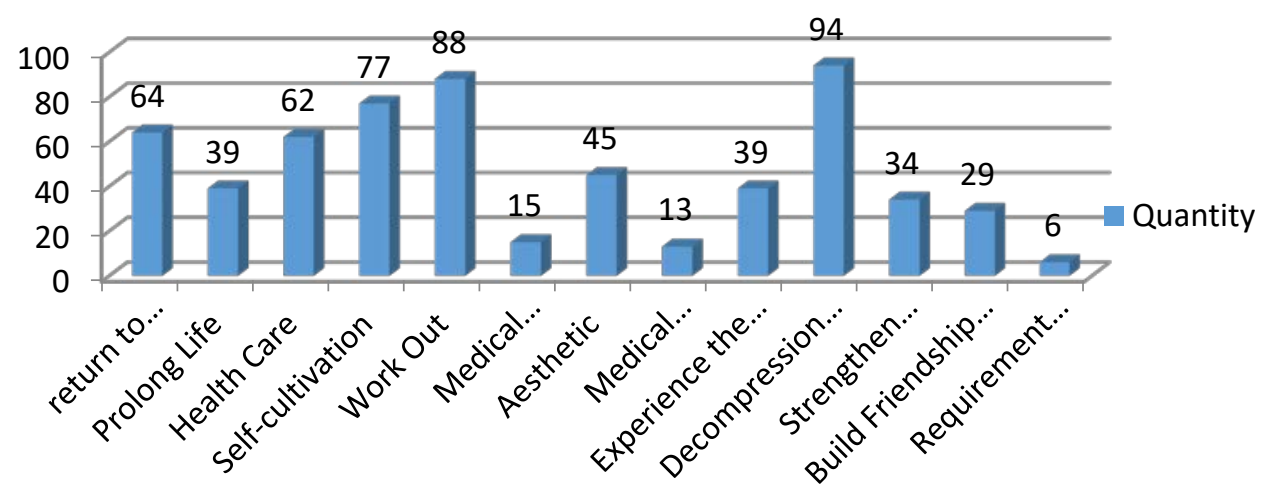

Figure 1. Research of Marketing Purpose of Wellness Leisure Tourism in Changchun City

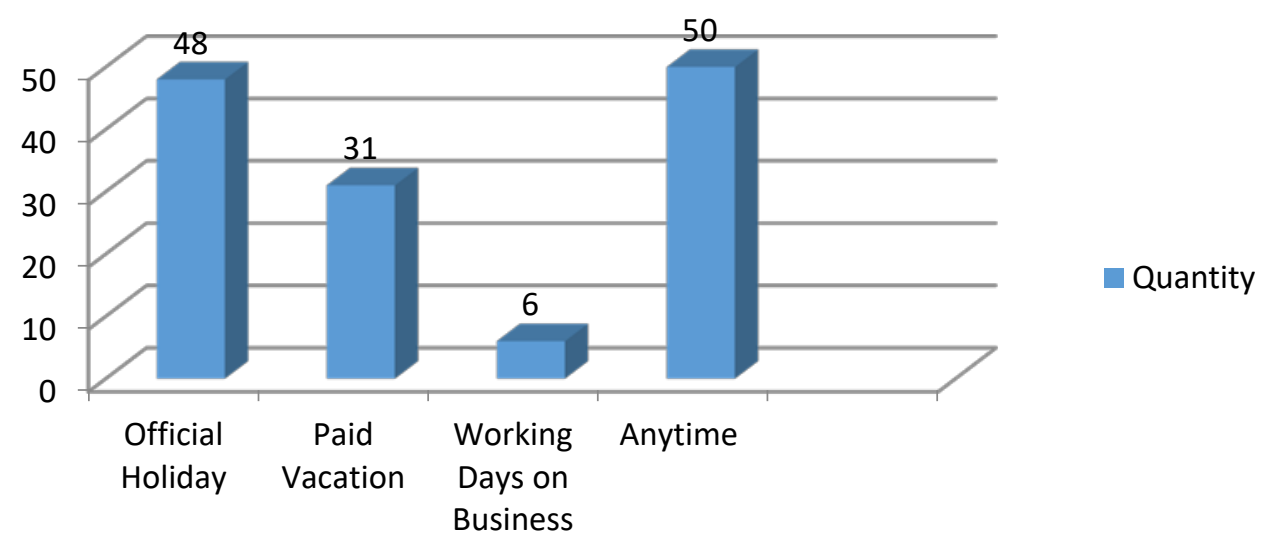

Figure 2. Time for Going for Wellness Tour Concluded from Changchun Tourism Market

The component and weight evaluation of the ideal purpose of wellness tourism in suburban areas of Changchun city are demonstrated as in Table 1, and people are concerning more about the comfortable weather, beautiful scenery and clean environment in the related field. The top three of the most important elements are fresh air, high quality service and high quality accommodation. Some elements are being ignored for importance, like the development status of local region, the quantity of recreation facilities and the clear guideposts along the way of journey. To conclude the said information, the most important elements consumers are paying attention to are fresh air and high quality service and accommodation.

Table 1. Component and Weight Evaluation of the Ideal Purpose of Wellness Tourism in Suburban Areas of Changchun City

\begin{tabular}{|c|c|c|c|c|c|}
\hline & $\begin{array}{c}\text { Irrelevant } \\
\text { (Person) }\end{array}$ & $\begin{array}{c}\text { Not } \\
\text { Important } \\
\text { (Person) }\end{array}$ & $\begin{array}{c}\text { Not Sure } \\
\text { (Person) }\end{array}$ & $\begin{array}{c}\text { Important } \\
\text { (Person) }\end{array}$ & $\begin{array}{c}\text { Very Important } \\
\text { (Person) }\end{array}$ \\
\hline 1. Comfortable Weather & 2 & 5 & 9 & 87 & 40 \\
\hline 2. Fresh Air & 0 & 3 & 6 & 72 & 61 \\
\hline 3. Beautiful Scenery & 0 & 7 & 16 & 87 & 33 \\
\hline 4. High Quality Service & 0 & 3 & 12 & 71 & 55 \\
\hline 5. Reasonable Price & 0 & 1 & 12 & 81 & 48 \\
\hline $\begin{array}{c}\text { 6. Convenient } \\
\text { Transportation }\end{array}$ & 0 & 9 & 15 & 81 & 37 \\
\hline $\begin{array}{c}\text { 7. Clear Guidepost along the } \\
\text { Journey }\end{array}$ & 3 & 13 & 40 & 58 & 32 \\
\hline 8. Clean Environment & 1 & 5 & 8 & 85 & 47 \\
\hline $\begin{array}{c}\text { 9. High Quality } \\
\text { Accommodation }\end{array}$ & 1 & 5 & 15 & 75 & 50 \\
\hline 10. Various Activities & 2 & 19 & 45 & 55 & 25 \\
\hline
\end{tabular}




\section{Strategy for developing Wellness Tourism in Suburban Areas of Changchun City}

\subsection{Government guides and regulates the market of tourism, and conducts the plan for wellness tourism industry in suburban areas of Changchun city.}

Changchun city is orientated as the International City for Ecological Tourism, as to forge the City of Forest Tourism. The city shall fulfill its three main functions which are concentrating the tourism (tourism transport center in Jilin province and (tourism transport center in Northeastern China), providing one-stop service for tourism destination and building public recreation and leisure for urban resident. Through building four international leisure resorts, like Jingyuetan, Lianhuashan, Shuangyang and Jiutai International Leisure Resorts, Changchun also recognizes the tourism industry as the dynamic industry. Changchun promotes itself as the famous city for skiing and spending summer. Thus, Changchun shall mainly and greatly promote and market the activities like skiing in winter and summer resort in summer for wellness tourism in its suburban areas.

\subsection{Accurate Market Orientation for Wellness Tourism in Suburban Areas of Changchun City}

The wellness tourism in suburban areas of Changchun city is generally orientated as the characteristics of wellness, leisure, health and fashion. Domestic market of tourist source: (1).Tourists in Northeast China give priority to self-drive travel, seniors, family leisure tourism and business award tourism. (2) Tourists in the Yellow sea and Bohai regions give priority to summer resort tourism, self-drive tourism, ice-snow tourism, business award tourism exercise and fitness tourism. (3) Tourists in Yangzi River delta region give priority to summer resort tourism, ice-snow tourism and folk culture tourism. (4) Tourists in Pearl River delta give priority to summer resort tourism, ice-snow tourism, folk culture tourism and food and delight tourism. Inbound tourism market: 1) Tourists in Hong Kong, Macau and Taiwan mainly give priority to summer resort tourism, ice-snow tourism and folk culture tourism. 2) Tourists in Japan and South Korea give priority to sightseeing tourism, historical culture tourism, seniors, and family tourism and golf activities. 3) Tourists in Russia give priority to health tourism and family tourism. 4. Tourists in Europe and America give priority to ice-snow tourism and folk culture tourism.

\subsection{Wellness for Four Seasons of Wellness Tourism in Suburban Tourism of Changchun City}

On the basis of wellness for four seasons, Changchun orientates its spring wellness tourism products as flower-viewing tour, forest outing tour and hot spring healthy wellness tour. The summer products are orientated as moistening lung wellness tourism by abundant water resource (river, lake, reservoir and wet land), forest bath wellness tourism, mountainous activities wellness tourism and folk culture wellness tourism. The products for autumn are orientated as dietetic life-nourishing tourism (corn, the local special product), traditional Chinese medicine tourism (sika deer products), forest bath wellness tourism, mountainous activities wellness tourism and outdoor exercise wellness tourism. The winter products are orientated as colorful the ice-snow wellness tourism brand integrating skiing, hot spring and food, including ice-snow tourism (skiing, winter swimming, skating and entertainment on ice), hot spring wellness tourism and food and drink wellness tourism.

\section{Summary}

As China seeks to revive the northeastern old industrial base, under the background of implementing national strategy for developing Changchun-Jilin-Tumen and cities around Harbin and Changchun, the new prospect of wellness tourism is presented. As Changchun enjoys its exceptional advantage in geographic position and complete industrial chain, it can meet the requirement of industrial restructuring, greatly boost the tertiary industry and serve the local economy. As a result, Changchun will welcome the bright future with wide open development space for wellness tourism.

\section{Acknowledgments}

This work was financially supported by "Jilin Provincial Department of Education "12th Five-Year" Social Science Research Project (2014B088)” 


\section{References}

[1] Di Jinna. Research of Wellness Tourism Development in Jilin [D]. Changchun: Northeast Normal University. 2014.

[2] Changchun Tourist Administration Official Website [OL]. http : // www. ccta. gov. Cn / zwdt / ght j/ lygh /index. html.

[3] Zhou Bo, Fang Wei. Research Review of Domestic Wellness Tourism [J] Tourism Forum. 2012

[4] Meng Minghao, Gu Xiaoyan. Research of Wellness Tourism in Suburban Areas Development in Recent Years [J] Tourism Tribune. 2002. 